\title{
Optimizing the Effect of Temperature-Time Combinations on the Quality Attributes of Roasted Cashew (Anacardium occidentale) Kernel
}

\author{
Olatidoye OP${ }^{1 *}$, Awonorin $\mathrm{SO}^{2}$, Shittu $\mathrm{TA}^{2}$, Ajisegiri ESA ${ }^{3}$, Sobowale $\mathrm{SS}^{4}$ and Adebo $\mathrm{OA}^{5}$ \\ ${ }^{1}$ Department of Food Technology, Yaba College of Technology, Nigeria \\ ${ }^{2}$ Department of Food Science and Technology, Federal University of Agriculture, Nigeria \\ ${ }^{3}$ Department of Agricultural Engineering, Federal University of Agriculture, Nigeria \\ ${ }^{4}$ Department of Food Technology, Mashood Abiola Polytechnic College, Nigeria \\ ${ }^{5}$ Department of Biotechnology and Food Technology, Faculty of Science, University of Johannesburg, South Africa
}

\begin{abstract}
The use of inappropriate temperature-time combinations during roasting of nuts could lead to quality defects, such as burnt taste, dark colour, short shelf-life, rancidity, and poor flavour. The objective of this study was to determine the effect roasting temperature $\left(100-160^{\circ} \mathrm{C}\right)$ and time $(20-60 \mathrm{~min})$ on colour parameters $\left(\mathrm{L}^{*}\right.$, $\mathrm{a}^{*}$, and $\mathrm{b}^{*}$ values), Browning Index (BI), Hardness, consumer acceptability and moisture content of both whole cashew-kernel and cashew nut paste using Response Surface Methodology. The experimental runs were established using central composite rotatable design. Second-order polynomial models were developed for predicting the determined product properties. The results showed that CIELAB $L^{*}$-value of the colour decreased from 54.41 to 41.23 while $a^{*}$ - and $b^{*}$ values increased from 6.08 to 15.84 and 13.77 to 25.92 , respectively, $p<0.05$ as the temperature and time increased. The moisture content and hardness decreased from 6.35 to $1.02 \%$ and 34.24 to $19.94 \mathrm{~N}$, respectively, while $\mathrm{BI}$ increased from 47.47 to 97.94 as the temperature and time increased. The results showed that colour parameters $\left(\mathrm{L}^{*}, \mathrm{a}^{*}, \mathrm{~b}^{*}\right.$-values, $\left.\mathrm{BI}\right)$ of whole cashew-kernel and $\mathrm{a}^{*}$-values of cashew nut paste could be used to monitor the roasting quality of cashew nut. The regression models significantly described the changes in moisture, hardness and colour parameters at $p<0.05\left(R^{2}=0.96\right)$. The recommended range of roasting temperature and time of wholekernel for cashew paste was $145^{\circ} \mathrm{C}$ and 40 min with desirability of 0.85 which is measure of goodness of fit of RSM model. The study showed that the optimized processing conditions produced acceptable cashew kernel and paste of desirable colour and superior flavour quality with short processing time that will enhance direct and commercial utilization.
\end{abstract}

Keywords: Roasting; Cashew-kernel; Response surface methodology; Temperature; Time

\section{Introduction}

Edible nuts are cultivated and grown in a variety of growing conditions and climates, and are valued for their sensory, nutritional, and health attributes. Typically, edible nuts are rich sources of lipids and proteins; also contain certain vitamins and minerals in appreciable amounts. The cashew plant, Anacadium ocidentale is one of the important tropical crops called "poor man's crop, rich man's food" [1]. The name cashew is derived from ACAJU, a Portuegese word. Nigeria is the leading producer of cashew in Africa and second world producer of cashew, producing $40.7 \%$ of total world production [2]. Cashew nut surplus of Nigeria is more than 50,000 tons per year which has a significant negative impact on Nigeria economy. Cashew nut is the main product traded in international market and is widely consumed as roasted, fried, salted or sugared snacks, as material for confectionery, bakery products and as a food ingredient [3], especially because it contains vital minerals which are seldom found in daily diets [4]. In order to increase export of processed cashew nut and extend its market in the world, improvement of quality of processed cashew nut is necessary. The final quality of roasted cashew nut is influenced by the design of the roaster and time-temperature profile used. Roasting is the most important steps in cashew nut processing, improvement of roasting process will contribute to improvement of processed cashew nut products. Temperature and time of roasting are two of the main factors that affect industrial roasting process which affect the drying, heat transfer rate and physico-chemical changes that occur protein and carbohydrate. The use of inappropriate temperature and time combination lead to quality defects such as short shelf life, discoloration, rancidity and poor flavor. Therefore, determination of roasting conditions (temperature- time combinations) more precisely and adhering to best conditions for roasting would ensure the production of good quality whole cashew nut and cashew nut paste. The effects of time-temperature profile on the kernel colour, moisture content and roasted cashew nut sensory properties have not been reported. Currently, integrated studies are lacking on elucidating the effects of roast degree of cashew nut under different time-temperature condition on the physical and chemical properties of cashew nut. Since roasting affects the product quality, control of the roasting process is significant because producers of cashew considered that determination optimum conditions for roasting cashew was a major problem. Hence, it is necessary to optimize the hot air roasting process to provide an acceptable product with a shorter processing time. Also, this information is necessary for improvement and design of roasting process for maximizing nutrient retention. Also, the changes in the sugar properties of nut during roasting have been studied. There is no or scarce report showing changes in carbohydrate profile of fresh and roasted cashew nut. However, a common problem with roasting process is the darkening of the finished product which in

*Corresponding author: Olatidoye OP, Department of Food Technology, Yaba College of Technology, Nigeria, Tel: +2348037284556; E-mail: waleolatidoye@gmail.com

Received November 22, 2017; Accepted December 20, 2017; Published December 26, 2017

Citation: Olatidoye OP, Awonorin SO, Shittu TA, Ajisegiri ESA, Sobowale SS, et al. (2017) Optimizing the Effect of Temperature-Time Combinations on the Quality Attributes of Roasted Cashew (Anacardium occidentale) Kernel. J Bioprocess Biotech 7: 313. doi:10.4172/2155-9821.1000313

Copyright: () 2017 Olatidoye OP, et al. This is an open-access article distributed under the terms of the Creative Commons Attribution License, which permits unrestricted use, distribution, and reproduction in any medium, provided the original author and source are credited. 
turn affects the consumer acceptability [5]. Visual examination is the common method of judging the colour of roasted nuts. This process of colour estimation is grossly subjective, hence measuring the colour by employing a modern colorimeter to produce optically and electronically the physiological sensation of human eye [6] can be used as a standard method and for developing colour sorting device [5]. Measurement of cashew nut colour has been suggested as an indirect index of severity of roasting [7]. Colour measurement is important in design, simulation and optimization process. Changes in free amino and total amino acid composition during roasting of several nut have been studied, there is limited study about changes in amino acid composition of cashew nut during roasting. Therefore, it is necessary to understand these changes during roasting so as to obtain a better quality roasted cashew nut. Flavor, crispy and crunchy texture is not usually monitored by the industry and sometimes required by the customers. Therefore, there is need to established reference range values for the sensory and physical characteristics of cashew nut to compare with those of the experimental samples in order to establish ranges of characteristics. Roasting is one of the most important processes giving necessary alterations to the product. Roasted cashew nuts are widely consumed as an appetizer and as raw materials in sweets, confectionary, chocolate and biscuits. For the processing industry and the catering business it is important to predict the roasting behaviour and the quality of cashew nut. Therefore, the main objective of this study is to establish the optimum processing conditions for roasting cashew kernel based on moisture content, sensory and textural quality parameters for the production of whole cashew-kernel and paste.

\section{Materials and Methods}

\section{Materials}

Freshly harvested and sun dried "Brazilian Jumbo" cashew nuts (Anacardium occidentale $L$ ) were purchased at maturity from plantation of Cocoa Research Institute of Nigeria (CRIN), Ibadan, Nigeria. The dried raw cashew nuts were sorted and the diseased and immature nuts were discarded and spread on the floor until further processing is required.

\section{Cashew nut processing}

Raw cashew nuts were steamed boiled using a steam boiler at a pressure of $0.62 \mathrm{MPa}$ for $40 \mathrm{~min}$ contact time between steam and cashew nuts by the modified method of [8]. The steamed nuts were cooled for $24 \mathrm{~h}$ and shelled using a foot-pedaled shelling machine. It makes use of a pair of knife each shaped into the contour of half nut. When the knives come together by means of a foot operated lever, they cut through the shell around the nut, leaving the kernel untouched. The kernel is then removed from the shell using a small metal tool resembling pen knife to remove the kernel from the nuts. The kernels were then pre-dried in a cabinet drier (Model LEEC F2, LEEC Ltd, Colwick, Nottingham) at a temperature of $60^{\circ} \mathrm{C}$ for $3 \mathrm{~h}$ to allow for the easy removal of the peels from the kernel. The peeled kernels were then packaged in glass bottles for the roasting process.

\section{Roasting process}

An experimental hot-air roaster was used for the roasting experiment. The roaster (forced air pilot scale roaster, Model- HRDH71 Laboratory oven) consisted of an internal size 450 by 450 by 350 $\mathrm{mm}$, temperature precision $\pm 0.1^{\circ} \mathrm{C}$, temperature range 50 to $250^{\circ} \mathrm{C}$, temperature stability of $\pm 0.5^{\circ} \mathrm{C}$, power- $1300 \mathrm{~W}$, voltage/frequency of $220 \mathrm{~V} / 50 \mathrm{~Hz}$ ). The oven consisted of a heater, a centrifugal fan for generating an air stream, and a drying chamber. The temperature readings were taken from a digital indicator, and the electrical current in the resistance was regulated manually to keep the temperature at a preset value. Air velocity was measured by using an anemometer. Before roasting, temperature and velocity of air were set at the desired values indicated by the experimental design and the roaster was run for a time to achieve a steady state. Next, cashew kernel were placed in the oven at roasting air temperature of $100,120,140$, and $160^{\circ} \mathrm{C}$ for $20-60 \mathrm{~min}$ which represents the range commonly used in nut industry. Each nut sample was held in a rectangular tray $(10 \mathrm{~cm}$ by $15 \mathrm{~cm})$, air velocity was kept constant at $1.0 \mathrm{~m} / \mathrm{s}$ throughout experiment not to affect drying rate. Prior to placing the sample in the roasting chamber, the roaster was allowed to run for at least $2 \mathrm{~h}$ to obtain steady state condition. The kernel was placed Pyrex petri dish $(8.0 \mathrm{~cm}$ diameter $)$, as a single layer was then placed in the roasting chamber. Then, every $20 \mathrm{~min}$ for a period of 1 $\mathrm{h}$, one petri-dish was removed from the roasting chamber in less than $10 \mathrm{~s}$ so that steady state conditions were maintained during sampling. After completion of roasting, roasted cashew nut were cooled to room temperature immediately by blowing ambient air with minimum fan capacity. This was necessary to prevent after cooking and further moisture loss due to the residual heat content.

\section{Experimental design}

Air temperature $\left(\mathrm{x}_{1}\right)$ and roasting time $\left(\mathrm{x}_{2}\right)$ were independent variables. Ranges of variables selected according to the industrial roasting conditions commonly used such that the design contained the product roasted from very light roast to very dark roast. A 2-factor, 5-level rotatable central composite design (CCD) using Design-Expert Software Version 6.0 (Stat Ease software) [9] was used. The five levels of each of the two variables were coded as, $-1.414 ;-1 ; 0 ;+1 ;+1.414$ and 13 runs were analyzed in random order using Design-Expert software version 6.0 (Stat Ease software). The effect of these variables were analyzed on responses: L-value $\left(\mathrm{y}_{1}\right)$ representing lightness, a-value $\left(\mathrm{y}_{2}\right)$ greenness, b-value $\left(\mathrm{y}_{3}\right)$ redness, browning index $(\mathrm{BI})\left(\mathrm{y}_{4}\right)$, moisture content $\left(\mathrm{y}_{5}\right)$, hardness $\left(\mathrm{y}_{6}\right)$ and acceptability $\left(\mathrm{y}_{7}\right)$. A second order model was proposed for each response variable $(\mathrm{Y})$ given as:

$$
\mathrm{Y}=\mathrm{b}_{0}+\mathrm{b}_{1} \mathrm{x}_{1}+\mathrm{b}_{2} \mathrm{x}_{2}+\mathrm{b}_{3} \mathrm{x}_{1} \mathrm{x}_{2}+\mathrm{b}_{4} \mathrm{x}_{1}^{2}+\mathrm{b}_{5} \mathrm{x}_{2}^{2}
$$

where: $b_{0}, b_{1} b_{2} b_{3} b_{4}$ and $b_{5}$ are regression equation coefficients, and $\mathrm{Y}$ is the expected value of the response.

\section{Colour evaluation of roasted cashew nut}

Roasted samples were stored in the plastic bags and stored in a chiller at $4^{\circ} \mathrm{C}$ until used for colour measurement. All colour measurement was determined within 10 days of roasting. The measurements were conducted after milling each sample to constant grind size to obtain cashew nut paste. Outside colour of 20 randomly selected cashew kernels was measured for every sample referred to as whole cashew kernel measurement while measurement carried out after milling each sample to constant grind size was referred to as cashew paste measurement $[10,11]$. Commission Internationale de I'Eclairage (CIE) tristimulus $L^{*}$ $a^{*} b^{*}$ parameters for both whole cashew kernel and cashew nut paste were determined using colour meter (Color Tee PCMTM Colour Tee Associates. Inc., Clinton. NJ, USA). The colorimeter operates on the CIE $L^{*}, a^{*}, b^{*}$ colour scheme. The $L^{*}-, a^{*}$ and $b^{*}$ - values are the three dimensions of the measured colour which gives specific colour value of the material. L-value represents light dark spectrum with a range of 0 (black) to 100 (white), a-value represents green-red spectrum with a range of -60 (green) to +60 (red), b-value represents blue-yellow spectrum with a range of -60 (blue) to +60 (yellow) and 0 is neutral. The instrument was first standardized $\left(L^{*}=78.14, a^{*}=4.16, b^{*}=-5.97\right)$ with a 
Business Xerox $80 \mathrm{gm}^{-2}$ white paper with $136 \mathrm{CIE}$ whiteness D65. The colour meter was placed on the sample by allowing the sensor to touch the sample; multiple measurements of several points on samples were made. The browning index (BI) was also used to estimate the total colour changes during roasting $[12,13]$. The browning index was calculated as:

$$
\begin{aligned}
& B I(\text { Browning index })=\frac{100(X-0.31)}{0.17} \\
& X=\frac{a+1.75 L}{5.645 L+a-3.012 b}
\end{aligned}
$$

where: L-value represents light dark spectrum with a range of 0 (black) to 100 (white), a-value represents green-red spectrum with a range of -60 (green) to +60 (red), b-value represents blue-yellow spectrum with a range of -60 (blue) to +60 (yellow).

\section{Moisture content determination}

The moisture content was determined by the method described by [14]. About $5 \mathrm{~g}$ was weighed into petri-dish of a known weight. It was then dried in the oven at $105 \pm 1^{\circ} \mathrm{C}$ for $4 \mathrm{~h}$. The sample was cooled in desiccator and weighed. The moisture content was calculated as follows:

$$
\text { Percentage moisture }=\frac{M 1-M 0}{W} \times 100
$$

where: $M_{0}=$ Weight of sample+dish after drying; $M_{1}=$ Weight of sample+Dish before drying; $\mathrm{W}=$ Weight of sample.

\section{Texture measurement of cashew nut}

In the texture profile analysis test, cashew nuts were placed individually on the plate, and double compression was applied using a cylindrical probe (diameter $=5.0 \mathrm{~mm}$ ) at a test speed of $0.1 \mathrm{~mm} / \mathrm{s}$. The deformation was selected as $0.3 \mathrm{~mm}$ for the samples and the dimensions were measured over 3 kernels as length $3.30-3.50 \mathrm{~mm}$, width 1.85 $1.90 \mathrm{~mm}$ and thickness $0.90-0.95 \mathrm{~mm}$. Nuts were placed horizontally and force was applied on the thickness. Three measurements were performed for each sample. Hardness in Newton (maximum peak of first compression) was considered to evaluate textural properties derived from the force-time curves [15].

\section{Consumer acceptability test}

The panelists employed were staffs of the university who have no previous experience in sensory evaluation. 100 panelists, 50 males and 50 females, aged among 20-59 yrs participated in the consumer acceptance test whose education levels varied from secondary school to university. The samples were presented to the panelist in glass jar with three-digit number. They were asked to give judgment on how much they like or dislike colour, flavour, texture, taste and overall acceptability of the samples. A 9-point hedonic scale was used. All sessions were held in a sensory panel room kept at $22^{\circ} \mathrm{C}$ and equipped with partitioned booths and cold white fluorescent lights. Panelists were each provided with $50 \mathrm{ml}$ of water at room temperature to rinse their mouths after each sample. Every treatment was evaluated in three replications. The ratings were given numerical value from 1 (extremely inferior to $\mathrm{R}$ ) to 9 (extremely better than $\mathrm{R}$ ) and 5 (no difference) while $\mathrm{R}$ is the reference sample.

\section{Statistical analysis}

Data collected from all experiments were in triplicates and data expressed as means \pm standard deviations. The data were subjected to one-way analysis of variance (ANOVA) and differences between treatment means were separated using Duncan's Multiple Range Test (DMRT) out to assess significant differences between means $(\mathrm{p}<0.05)$. All statistical procedures were carried out according to methods of [16] while computation was done using SAS software package 17.0.

\section{Results and Discussion}

\section{Optimization of process variables and modeling}

The experimental values of colour dimensions of $\mathrm{L}^{*}-\mathrm{a}^{*}$, and $\mathrm{b}^{*}$ value for whole cashew-kernel and cashew nut paste measurement are presented in Tables 1-3. The L-value ranged from 41.23 to 54.41 for whole cashew-kernel measurements and from 48.25 to 36.80 for cashew nut paste over the experimental conditions. The $\mathrm{a}^{\star}$-values ranged from 6.08 to 15.84 for whole cashew-kernel measurement. It varied from 5.02 to 11.88 for cashew nut paste over the experimental conditions (Table 2). The mean $\mathrm{a}^{*}$-value of whole cashew-kernel measurements (10.4) was higher than the cashew nut paste measurement (8.78). The b-value ranged from 13.72 to 25.92 for whole cashew-kernel measurement while it ranged from 10.88 to 28.75 for cashew nut paste measurement. The browning index (BI) for whole cashew-kernel measurement ranged from 47.47 to 97.94 while cashew nut paste measurement ranged from 45.35 to 113.59. The moisture content of whole cashew-kernel measurement varied between 1.02 to $2.51 \%$, hardness varied between 19.94 to $32.24 \mathrm{~N}$ while consumer acceptability scores varied between 1.02 to 8.83. Summary of linear, quadratic and cross-product terms for $\mathrm{L}^{*}$-value, $\mathrm{a}^{*}$-value, $\mathrm{b}^{*}$-value of whole-kernel and ground-state were

\begin{tabular}{|c|c|c|c|c|}
\hline \multirow{2}{*}{ Run Number } & \multicolumn{2}{|c|}{ Coded } & \multicolumn{2}{|c|}{ Actual } \\
\hline & Temperature $\left({ }^{\circ} \mathrm{C}\right)$ & Time (min) & Temperature $\left({ }^{\circ} \mathrm{C}\right)$ & Time (min) \\
\hline 1 & 0 & 0 & 140 & 40 \\
\hline 2 & 0 & 0 & 140 & 40 \\
\hline 3 & 0 & 0 & 140 & 40 \\
\hline 4 & 0 & 0 & 140 & 40 \\
\hline 5 & 0 & 0 & 140 & 40 \\
\hline 6 & 0 & 1.414 & 140 & 54 \\
\hline 7 & 0 & -1.414 & 140 & 26 \\
\hline 8 & 1.414 & 0 & 154 & 40 \\
\hline 9 & -1.414 & 0 & 126 & 40 \\
\hline 10 & 1 & 1 & 150 & 50 \\
\hline 11 & -1 & 1 & 130 & 50 \\
\hline 12 & 1 & -1 & 150 & 30 \\
\hline 13 & -1 & -1 & 130 & 30 \\
\hline
\end{tabular}
given in Tables 4 and 5, respectively. The coefficient of determination varied from 0.8243 to 0.9861 for whole-kernel measurement and from

Table 1: Coded and Actual variables for the experimental design for the optimization of roasting process of cashew nut in hot-air oven. 
Citation: Olatidoye OP, Awonorin SO, Shittu TA, Ajisegiri ESA, Sobowale SS, et al. (2017) Optimizing the Effect of Temperature-Time Combinations on the Quality Attributes of Roasted Cashew (Anacardium occidentale) Kernel. J Bioprocess Biotech 7: 313. doi:10.4172/2155-9821.1000313

Page 4 of 11

\begin{tabular}{|c|c|c|c|c|c|c|c|c|}
\hline \multicolumn{9}{|c|}{ Whole-kernel measurement } \\
\hline Temperature $\left(0^{\circ} \mathrm{C}\right)$ & Time (min) & $\mathbf{L}^{*}$ & $a^{*}$ & $\mathbf{b}^{*}$ & BI & MC (\%) & Hardness (N) & Acceptability \\
\hline 126 & 40 & 46.74 & 8.45 & 13.72 & 47.47 & 2.51 & 34.24 & 1.02 \\
\hline 130 & 30 & 43.55 & 7.12 & 20.20 & 72.80 & 2.38 & 32.24 & 2.85 \\
\hline 130 & 50 & 41.23 & 6.08 & 18.10 & 67.34 & 2.11 & 28.22 & 3.48 \\
\hline 140 & 26 & 45.23 & 10.21 & 25.22 & 94.94 & 2.20 & 26.88 & 5.44 \\
\hline 140 & 40 & 42.89 & 9.85 & 24.49 & 97.94 & 1.51 & 26.10 & 7.63 \\
\hline 140 & 40 & 42.89 & 9.85 & 24.49 & 97.94 & 1.51 & 26.10 & 7.63 \\
\hline 140 & 40 & 42.89 & 9.85 & 24.49 & 97.94 & 1.51 & 26.10 & 7.63 \\
\hline 140 & 40 & 42.89 & 9.85 & 24.49 & 97.94 & 1.52 & 26.10 & 7.63 \\
\hline 140 & 40 & 42.89 & 9.85 & 24.49 & 97.94 & 1.50 & 26.10 & 7.63 \\
\hline 140 & 54 & 39.74 & 8.08 & 20.35 & 84.41 & 1.28 & 25.73 & 8.83 \\
\hline 150 & 30 & 51.88 & 15.84 & 25.92 & 89.59 & 1.31 & 24.12 & 8.03 \\
\hline 150 & 50 & 50.88 & 15.33 & 25.02 & 87.88 & 1.18 & 23.44 & 6.94 \\
\hline 154 & 40 & 54.41 & 14.84 & 23.24 & 84.00 & 1.02 & 19.94 & 6.41 \\
\hline
\end{tabular}

Table 2: Measured data for all response parameters of roasted whole cashew kernel.

\begin{tabular}{|c|c|c|c|c|c|}
\hline \multirow[b]{2}{*}{ Temperature ${ }^{\circ} \mathrm{C}$} & \multirow[b]{2}{*}{ Time(min) } & \multicolumn{4}{|c|}{ Cashew paste measurement } \\
\hline & & $L^{*}$-value & $a^{*}$-value & b*-value & BI \\
\hline 126 & 40 & 38.22 & 6.44 & 10.88 & 45.35 \\
\hline 130 & 30 & 36.80 & 5.42 & 22.11 & 97.88 \\
\hline 130 & 50 & 37.55 & 8.48 & 23.45 & 108.82 \\
\hline 140 & 26 & 35.21 & 5.02 & 21.20 & 97.78 \\
\hline 140 & 40 & 37.55 & 8.48 & 23.45 & 108.82 \\
\hline 140 & 40 & 37.55 & 8.48 & 23.45 & 108.82 \\
\hline 140 & 40 & 37.55 & 8.48 & 23.45 & 108.82 \\
\hline 140 & 40 & 37.55 & 8.48 & 23.45 & 108.82 \\
\hline 140 & 40 & 37.55 & 8.48 & 23.45 & 108.82 \\
\hline 140 & 54 & 38.75 & 11.68 & 25.79 & 123.78 \\
\hline 150 & 30 & 48.25 & 11.88 & 26.22 & 93.66 \\
\hline 150 & 50 & 46.50 & 11.25 & 27.45 & 102.82 \\
\hline 154 & 40 & 45.22 & 11.52 & 28.75 & 113.59 \\
\hline
\end{tabular}

Table 3: Measured data for all response parameters of roasted cashew nut paste.

\begin{tabular}{|c|c|c|c|c|c|c|c|}
\hline \multicolumn{5}{|c|}{ Colour parameters } & \multirow[b]{2}{*}{ MC } & \multirow[b]{2}{*}{ Hardness } & \multirow[b]{2}{*}{ Acceptability } \\
\hline & $L^{*}$ & $a^{*}$ & $\mathbf{b}^{*}$ & BI & & & \\
\hline Intercept & 42.89 & 10.4 & 24.49 & 97.94 & 1.51 & 26.37 & 8.03 \\
\hline A & $3.60^{*}$ & $3.38^{*}$ & $3.26^{*}$ & 11.14 & $-0.52^{*}$ & $-4.14^{*}$ & 2.17 \\
\hline B & $-1.39^{*}$ & -0.57 & $-1.24^{*}$ & -2.76 & $-0.21^{*}$ & -0.36 & 0.91 \\
\hline$A^{2}$ & $3.93^{*}$ & 0.00 & $-2.59^{*}$ & -15.66 & $0.13^{*}$ & 0.00 & $-2.04^{*}$ \\
\hline $\mathrm{B}^{2}$ & -0.11 & 0.00 & -0.43 & -3.71 & $0.13^{*}$ & 0.00 & -0.82 \\
\hline$A B$ & 0.33 & 0.00 & 0.30 & 0.94 & 0.000 & 0.00 & -0.14 \\
\hline $\begin{array}{c}\mathrm{R}^{2} \\
\text { Adj. } \mathrm{R}^{2}\end{array}$ & $\begin{array}{l}0.9620 \\
0.9349\end{array}$ & $\begin{array}{l}0.8243 \\
0.7891\end{array}$ & $\begin{array}{l}0.9500 \\
0.9142\end{array}$ & $\begin{array}{l}0.9861 \\
0.9762\end{array}$ & $\begin{array}{l}0.9545 \\
0.9219\end{array}$ & $\begin{array}{l}0.8674 \\
0.5828\end{array}$ & $\begin{array}{l}0.8978 \\
0.8248\end{array}$ \\
\hline F-Value & 35.45 & 23.45 & 26.58 & 99.32 & 29.35 & 32.70 & 12.30 \\
\hline $\begin{array}{l}\text { PRESS } \\
\text { CV } \\
\text { Lack of fit }\end{array}$ & $\begin{array}{c}64.57 \\
2.52 \\
9.08\end{array}$ & $\begin{array}{l}42.57 \\
13.60 \\
19.99\end{array}$ & $\begin{array}{c}54.06 \\
4.60 \\
7.60\end{array}$ & $\begin{array}{c}278.97 \\
2.74 \\
39.23\end{array}$ & $\begin{array}{l}0.93 \\
8.16 \\
0.13\end{array}$ & $\begin{array}{c}46.25 \\
5.51 \\
21.13\end{array}$ & $\begin{array}{c}61.30 \\
17.71 \\
8.62 \\
\end{array}$ \\
\hline
\end{tabular}

$\mathrm{Y}=\mathrm{b}_{0}+\mathrm{b}_{1} \mathrm{x}_{1}+\mathrm{b}_{2} \mathrm{x}_{2}+\mathrm{b}_{3} \mathrm{x}_{1} \mathrm{x}_{2}+\mathrm{b}_{4} \mathrm{x}_{1}^{2}+\mathrm{b}_{5} \mathrm{x}_{2}^{2}$

where $A=$ air temperature $\left({ }^{\circ} \mathrm{C}\right)$ and $B=$ roasting time $(\min )$; "Significant at $5 \%, B I=$ Browning index; $M C=$ Moisture content

Table 4: Regression equation coefficient, presented as actual terms and statistical analysis for response of roasted whole cashew kernel.

0.6988 to 0.8210 for cashew paste measurement. The adjusted coefficient of determination for whole-kernel measurement varied from 0.5828 to 0.9762 and from 0.5113 to 0.6954 for cashew paste measurement. The F-value for whole-kernel measurement ranged from 99.32 to 12.39 while the paste measurement ranged from 3.51 to 14.70 . The regression equations obtained were used to generate response surfaces which are presented in Figures 1-11. The shape of response surfaces differed between measurement methods. The response surface of $L^{*}$-value of whole kernel measurements were vertically displayed to significantly lower $L^{\star}$-value $(p<0.05)$ in the cashew paste measurements. The response surfaces of a-value of whole-kernel measurement were vertically displayed to significantly higher a-value $(\mathrm{p} \leq 0.05)$ in cashew paste measurement. Colour can be used for process control and roasting operations, which are controlled by the degree of colour formation because the brown pigments increase as browning and caramelization reactions progress [17]. Colour is one of the most important appearance 


\begin{tabular}{|c|c|c|c|c|}
\hline \multicolumn{5}{|c|}{ Colour parameters } \\
\hline & $\mathbf{L}^{*}$ & $\mathbf{a}^{*}$ & $\mathbf{b}^{*}$ & $\mathbf{B I}$ \\
\hline INTERCEPTS & 37.55 & 8.34 & 23.36 & 108.82 \\
\hline $\mathrm{A}$ & $4.08^{*}$ & $2.31^{*}$ & $4.45^{*}$ & $12.71^{*}$ \\
\hline $\mathrm{B}$ & 0.14 & 0.83 & 1.34 & 8.82 \\
\hline $\mathrm{A}^{2}$ & $2.69^{*}$ & 0.00 & 0.00 & $-15.61^{*}$ \\
\hline $\mathrm{B}^{2}$ & 0.23 & 0.00 & 0.00 & 5.18 \\
\hline $\mathrm{AB}$ & -0.04 & 0.00 & 0.00 & 2.32 \\
\hline $\mathrm{R}^{2}$ & 0.8210 & 0.7462 & 0.6988 & 0.7149 \\
\hline Adj. R & 0.6931 & 0.6954 & 0.6386 & 0.5113 \\
\hline F-VALUE & 6.42 & 14.70 & 11.60 & 3.51 \\
\hline PRESS & 285.11 & 36.05 & 164.60 & 11344.35 \\
\hline CV & 6.08 & 15.35 & 11.69 & 14.47 \\
\hline
\end{tabular}

$\mathrm{Y}=\mathrm{b}_{0}+\mathrm{b}_{1} \mathrm{x}_{1}+\mathrm{b}_{2} \mathrm{x}_{2}+\mathrm{b}_{3} \mathrm{x}_{1} \mathrm{x}_{2}+\mathrm{b}_{4} \mathrm{x}_{1}^{2}+\mathrm{b}_{5} \mathrm{x}_{2}^{2}$

where $A=$ air temperature $\left({ }^{\circ} \mathrm{C}\right)$ and $B=$ roasting time $(\mathrm{min})$; "Significant at $5 \%$, $\mathrm{Bl}=$ Browning index

Table 5: Regression equation coefficient, presented as actual terms and statistical analysis for response of roasted cashew paste.
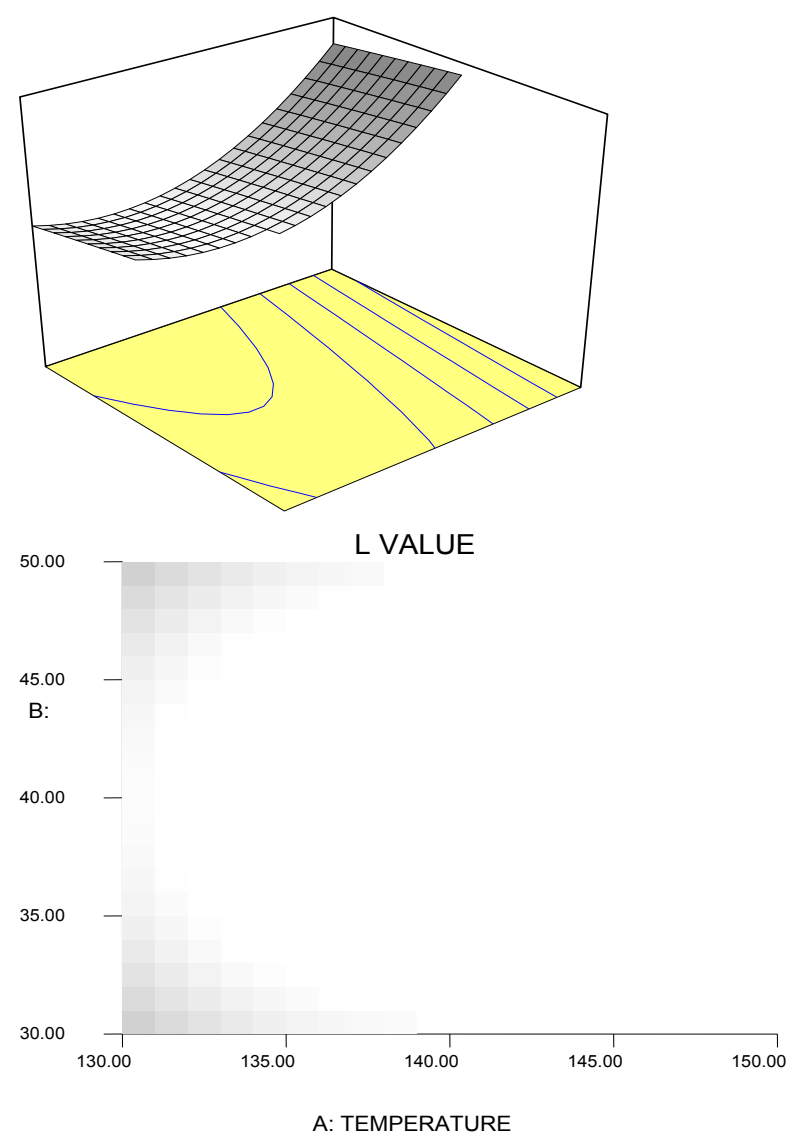

Figure 1: Response surface and contour plots for L-value of whole-kernel measurement as affected by roasting temperature and time of roasted cashew kernel.

attributes of food materials, as it influences consumer acceptability [18]. Besides consumer acceptability, colour is also used in process control. The degree of colour formation is used for roasting operation control because the brown pigments increase as the browning and caramelization reactions progress [17]. The effect of independent variable: temperature and time on each variable was divided into first order (linear), second in maillard reactions. An increase in temperature for longer time leads to an increase of the reactivity between the sugar and the amino group $[19,20]$. It was previously shown that as temperature and time increased, similar results were obtained in $\mathrm{L}^{*}$ and $\mathrm{a}^{*}$ values during conventional roasting hazelnuts $[17,21,22]$. Regression equations obtained were used to generate response surfaces. The shape of response surface differed between measurement methods. The response surface of L-value of whole kernel measurement vertically displayed to significantly lower $\mathrm{L}$-value $(\mathrm{p}<0.05)$ in cashew paste. The $\mathrm{L}$-value ranged from 41.23 to 54.41 for whole kernel measurement and from 35.21 to 48.25 for cashew paste measurement over the experimental conditions. The mean L-value of whole-kernel measurement $(64.22 \pm 3.53)$ was higher than the cashew
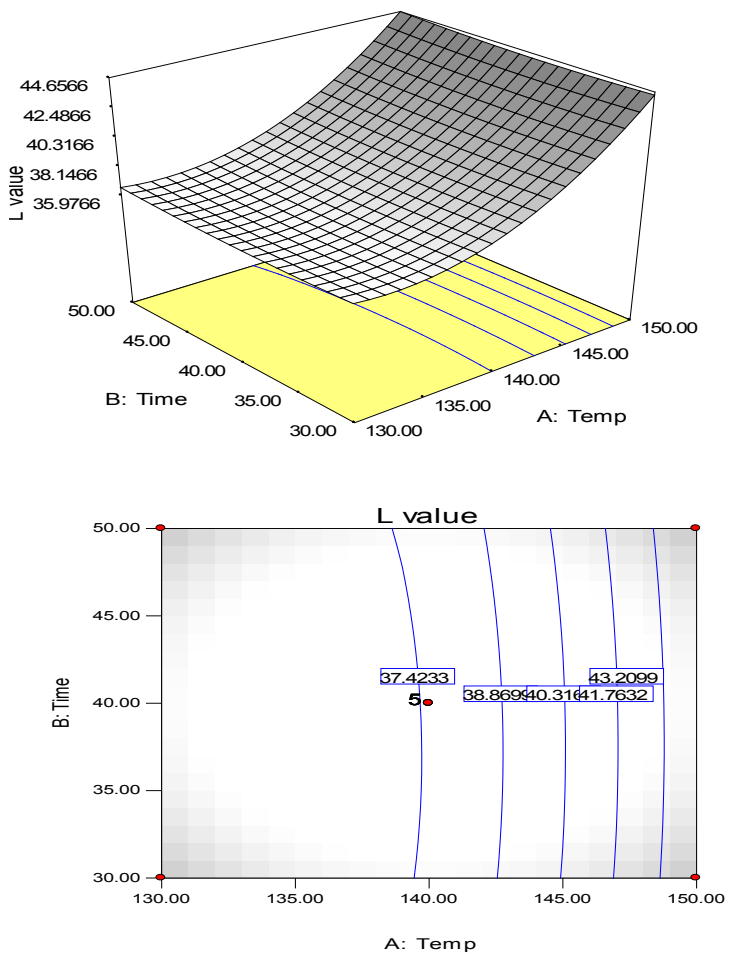

Figure 2: Response surface and contour plots for L-value of ground-state as affected by roasting temperature and time for roasted cashew kernel.

order (quadratic) and interactive effects (interaction between pairs of variables). By using lack-of-fit and coefficient of determination $\left(\mathrm{R}^{2}\right)$, adequacy of the model can be determined. The significance of equation parameter for all response variables was also assessed by F-ratio at a probability (p) of 0.05 ; [18] suggested $\mathrm{R}^{2}$ should be at least 0.80 to have a good fit of the model. The closer the value of $\mathrm{R}^{2}$ to unity, the better the empirical model fits the actual data. The low $\mathrm{R}^{2}$ value observed for colour, $\mathrm{a}^{\star}(0.7462)$ and $\mathrm{b}^{\star}(0.6988)$ for cashew paste indicates that $\mathrm{a}^{\star}$ and $\mathrm{b}^{*}$ in cashew kernel was influenced by the roasting temperature and time as suggested by RSM. All the colour parameters have significant linear and quadratic model and not significant lack of fit. The coefficient of determination was quite high for all of the quality parameters. It can be seen from the model equation that $\mathrm{a}^{*}$ and $\mathrm{L}^{*}$ values changed with roasting temperature and roasting time. As the roasting temperature and time increased, $a^{*}$ value of the colour dimension increased but $\mathrm{L}$-value decreased. The increase in $\mathrm{a}^{*}$ value represent the increase in the reddish colour and the decrease in $\mathrm{L}^{*}$ value represents the darker colour of cashew kernel due to the formation of brown pigments through 

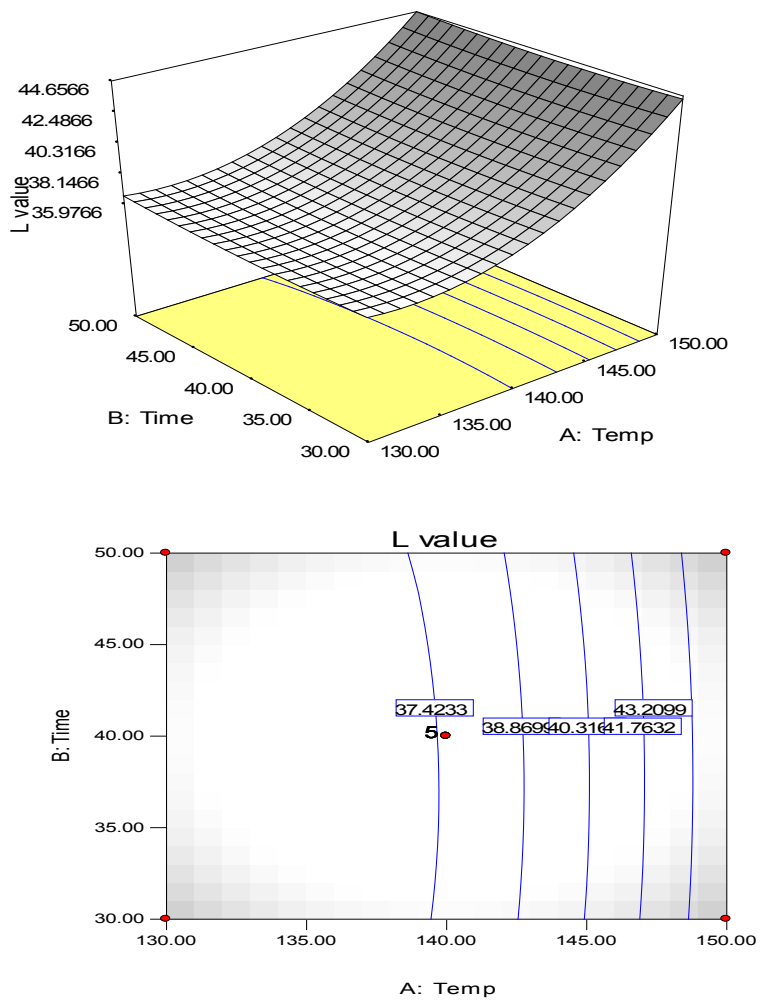

Figure 3: Response surface and contour plots for a-value of whole-kerne measurement as affected by roasting temperature and time of roasted cashew kernel.
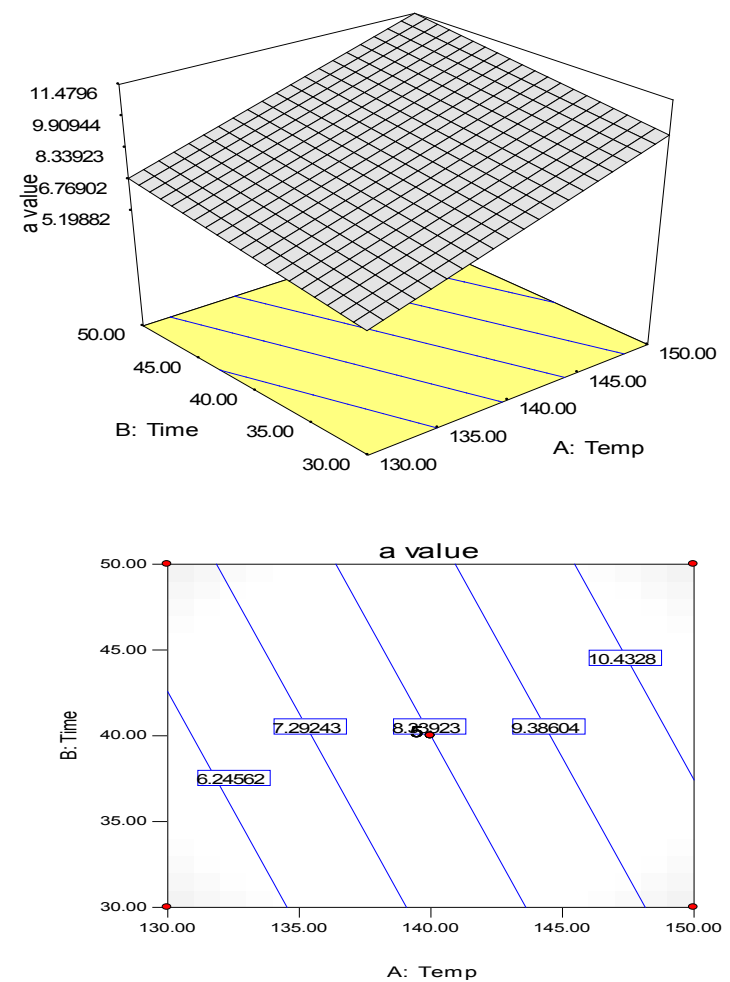

Figure 4: Response surface and contour plots for a-value of ground-state measurement as affected by roasting temperature and time for roasted cashew kernel.
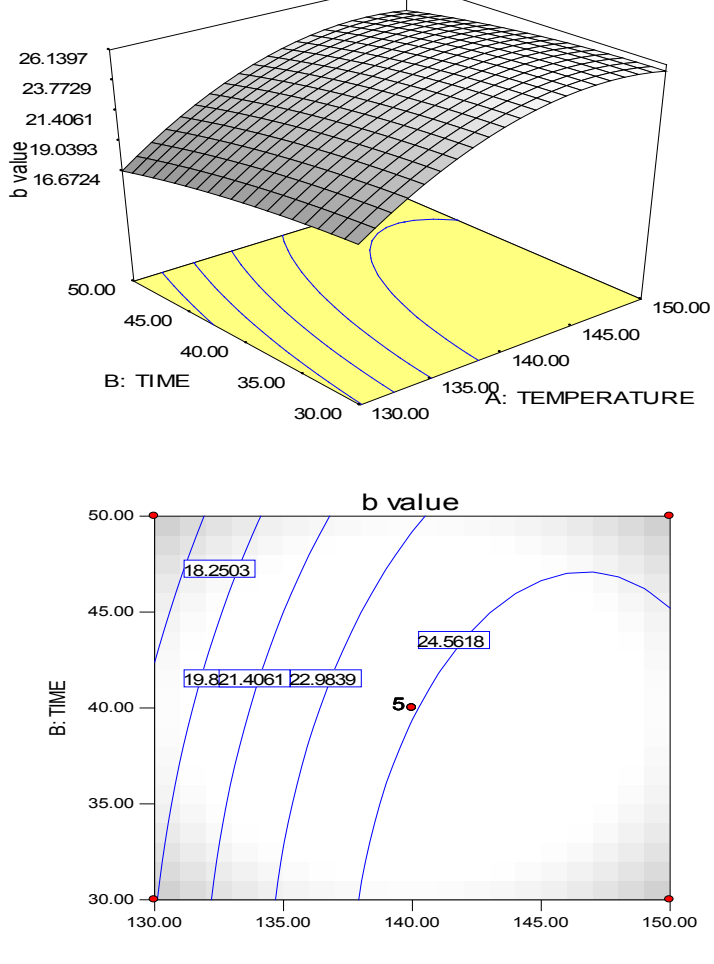

Figure 5: Response surface and contour plots for b-value of whole-kernel measurement as affected by roasting temperature and time for roasted cashew kernel.
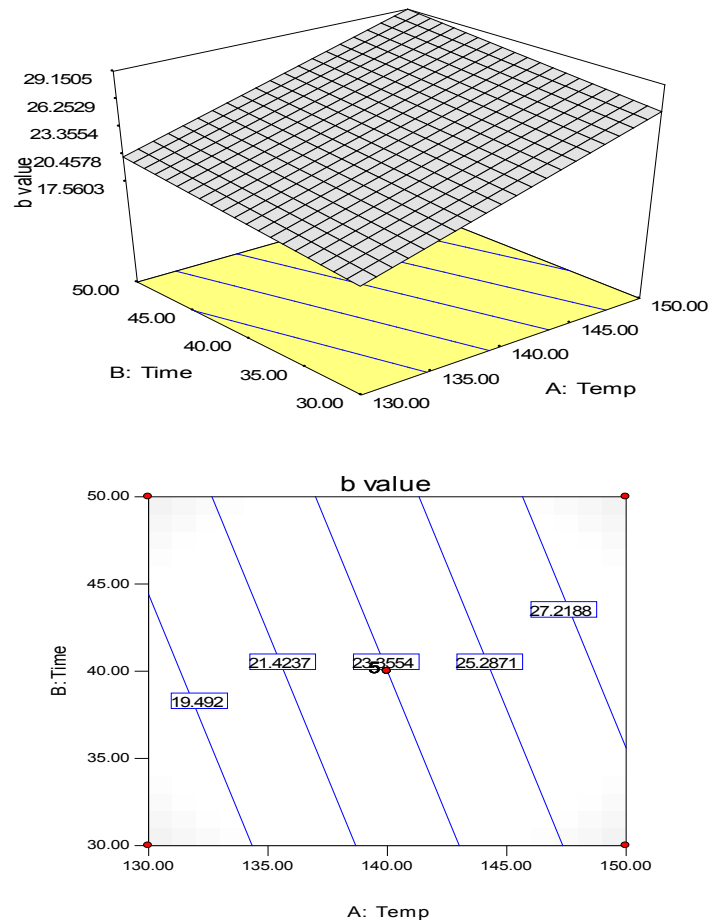

Figure 6: Response surface and contour plots for b-value of ground- state measurement as affected by roasting temperature and time of roasted cashew kernel. 

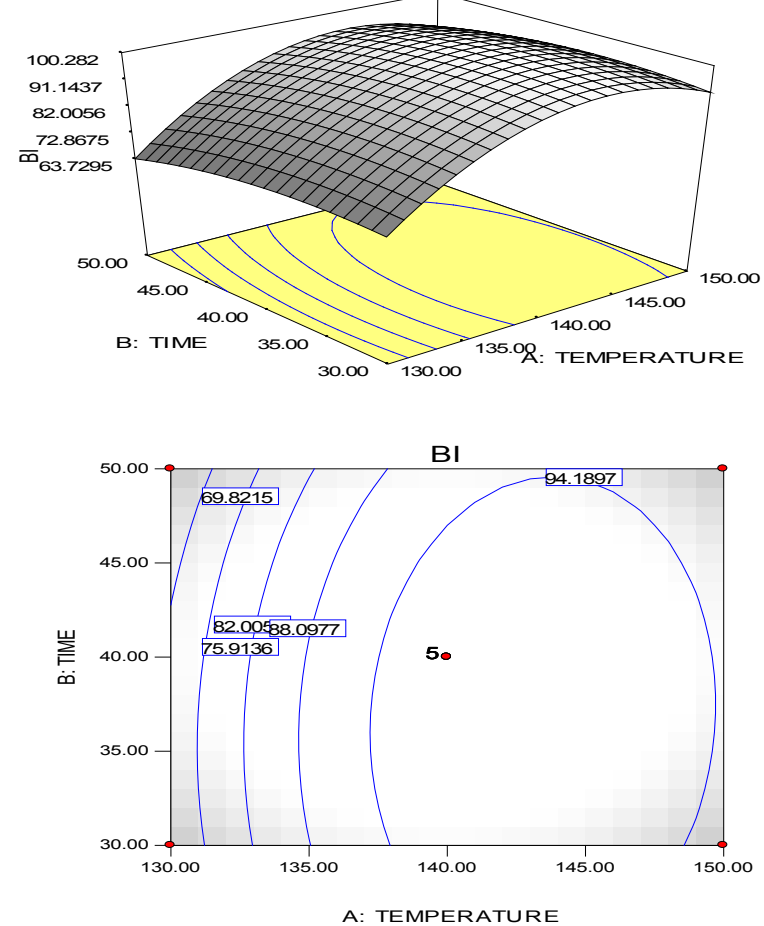

Figure 7: Response surface and contour plots for Browning index of wholekernel measurement as affected by roasting temperature and time for roasted cashew kernel.
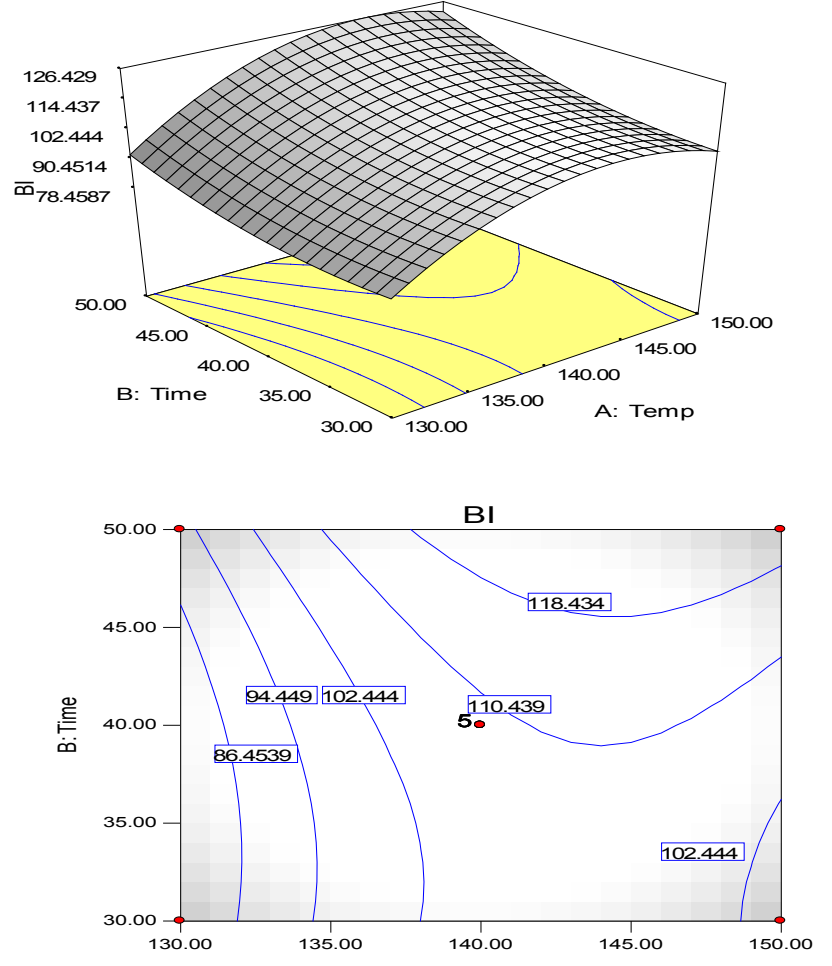

Figure 8: Response surface and contour plots for Browning index of groundstate measurement as affected by roasting temperature and time for roasted cashew kernel.

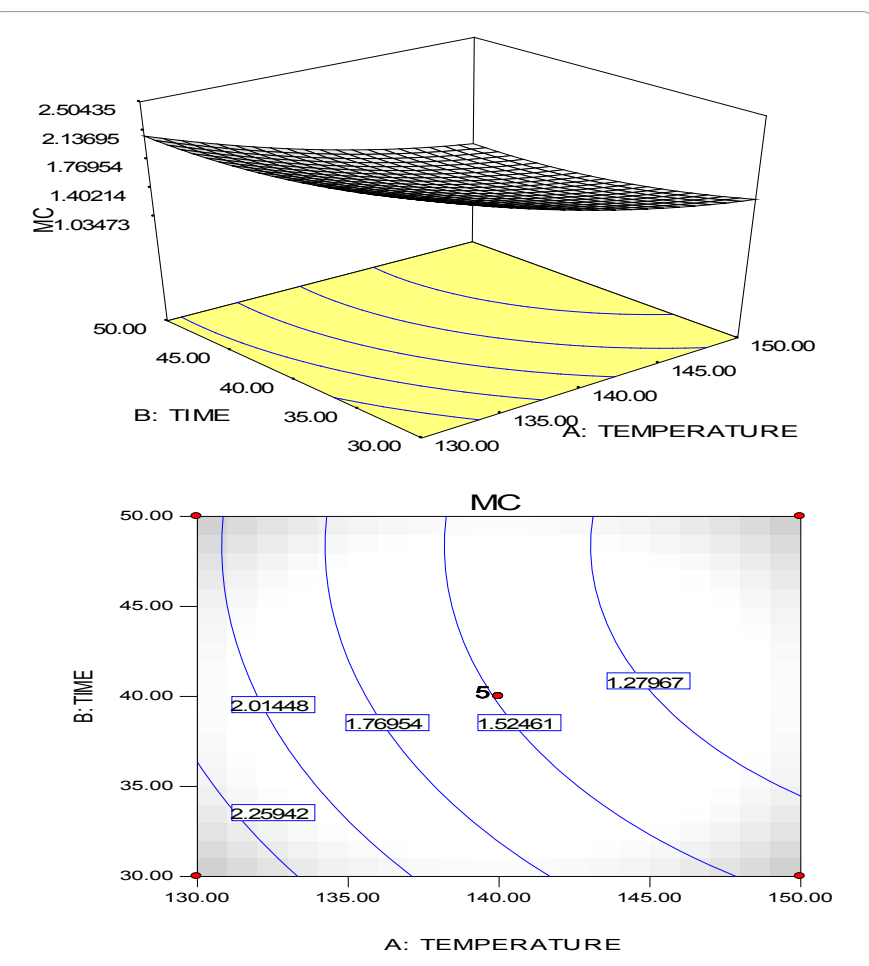

Figure 9: Response surface and contour plots for whole kernel moisture content measurement as affected by roasting temperature and time of roasted Cashew kernel.
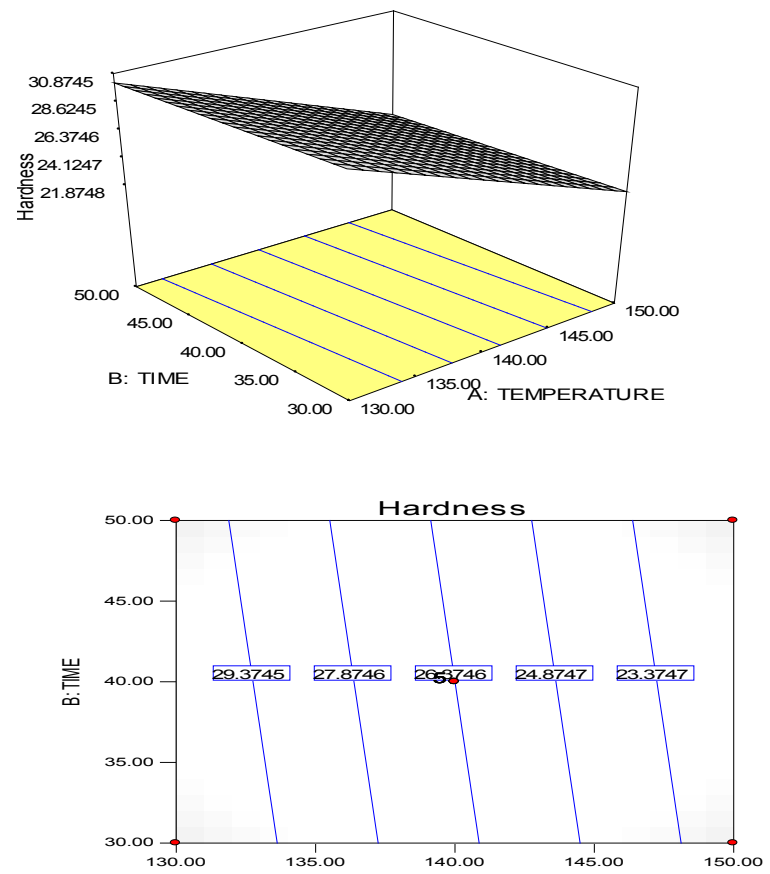

Figure 10: Response surface and contour plots for whole kernel Hardness measurement as affected temperature and time for roasted cashew kernel.

maillard reactions. As the roasting temperature and time increased, cashew kernel interacted with oven conditions more. More heat was generated inside the cashew kernel leading to an increase in internal temperature for longer time. Temperature and time relation is important 

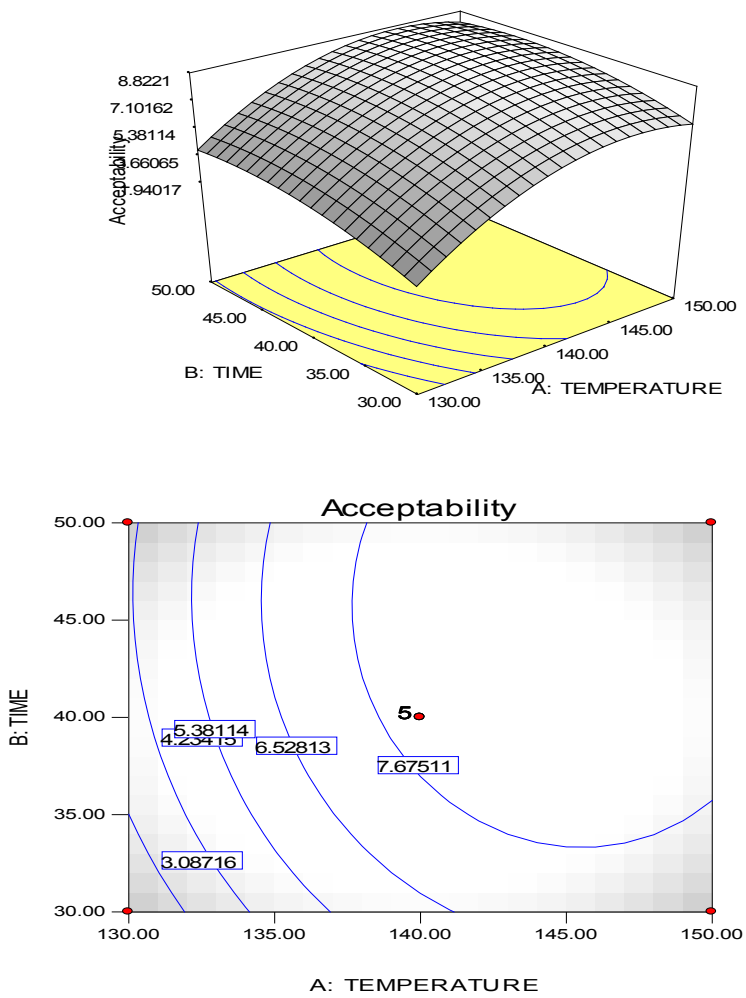

Figure 11: Response surface and contour plots for whole kernel acceptability measurement as affected by roasting temperature and time for roasted cashew kernel.

paste measurement (39.56 \pm 3.28$)$. L-value of whole kernel measurement remained vertically constant before a significant colour change was observed. This change was also observed by [23] during roasting of hazel nut. The correlation coefficients of regression equations for the colour parameters of the whole kernels and cashew paste changed from 0.82 to 0.99 and from 0.70 to 0.82 , respectively. According to lack of fit tests, it can be concluded that the proposed model estimates the response surfaces and can be used for prediction of L-value, b-value and BI of kernels and a-value of the ground kernel. The linear and quadratic terms of the roasting temperature had a significant effect on all colour parameters of the roasted whole-kernels and ground states except for the a-value and BI of ground-state. On the other hand, the interaction terms (roasting temperature and time) for the L, b-values and $\mathrm{BI}$ of kernel and $\mathrm{L}$ and $\mathrm{b}$-values of the ground-state were also found not to be significant $(\mathrm{p}<0.05)$. On the overall, except for the a-value of the kernel, and the b-value and BI of the ground-states, all other values studied were not significantly $(\mathrm{p}<0.05)$ affected by roasting time. It was observed that roasting temperature is the main factor that influences the $\mathrm{L}, \mathrm{a}, \mathrm{b}$-values, and $\mathrm{BI}$ of kernels and $\mathrm{L}, \mathrm{a}, \mathrm{b}$-values of cashew paste in the production of pistachio paste. In this study it was observed that both roasting temperature and time influence the changes in colour attributes of whole-kernels and cashew paste but the effect of temperature is more important than time. Similar findings were observed by $[7,22]$ in their studies on hazelnuts. The regression equations were used to run response plots for all the colour responses studied showed that the L-values which reflect the whiteness of wholekernels and ground-states ranged from 36.80 to 46.50 . The shape of $\mathrm{L}$-values observed at the beginning of the roasting period was due to initial lightening effect as reported in hazelnuts by [21-23]. But in contrast to this finding, whole pistachio nut did not show any initial lightening [24] similar to that found in whole-kernels and cashew paste. The shapes of the surface plots for L, b-values, and BI of kernel are similar to each other. All the values showed a decreasing trend at higher temperature and time. The shapes of the response surfaces were found to be different for a-value which showed falling ridge behaviour with temperature and time. The change in behavior is probably due to exposure to the high roasting temperature and the longer time. It was found that the redness (a-value) of kernels decreased gradually with increase in temperature and time and the whole-kernels were darker when they were roasted at $150^{\circ} \mathrm{C}$ for $30 \mathrm{~min}$ and $160^{\circ} \mathrm{C}$ for $40 \mathrm{~min}$. The response surface plots for whiteness (L-values) and yellowness (b-values) of cashew paste were saddle in shape. The a-values and BI showed a sharp, increasing and sharp decreasing behavior, respectively. This indicates that the redness of cashew paste increased whereas the yellowness decreased rapidly with the increase in roasting temperature and time. The initial colour of ground-state changed from 6.44 to 11.88 and it changed to red after roasting probability due to browning reactions between amino acid and reducing sugar in the cashew kernel. The result of RSM analysis showed that in term of colour parameters the L, b-values, and BI of kernels and a-values of ground-state should be monitored during roasting of whole-kernels. The response surface of a-value of whole kernel measurement is vertically displayed to significantly higher a-value $(\mathrm{p}<0.05)$ in cashew paste measurement. The a-value ranged from 5.42 to 11.68 for ground state, from 6.08 to 15.84 for whole kernel measurement over the experimental conditions. The mean a-value for whole-kernel measurement $(10.4 \pm 2.28)$ was higher than the ground state measurement $(8.78 \pm 1.73)$. The higher a-value in the whole kernel measurement related to an increase in redness an indication of the internal browning. The higher roasting temperature and longer exposure time resulted in the grater a-value and subsequently darker internal browning. The internal browning is a problem for the roasted product that are consumed as whole-kernel because the difference between outside colour and inside colour of roasted product makes the product unpleasant for the consumer. Similar internal browning was also reported by [24] in roasted hazel nut, by [25] in roasted almond and pecan. The internal browning may be due to differences in the rate of non-enzymatic browning between the outside and inside of the kernel. we found out that there was a significant difference between inner and outer layer of hazel nuts in terms of the protein and sugar content. This may probably be as a result of the concentration of sugar component in the inner layer of raw nuts compared to outer layer. Therefore, non- enzymatic browning reaction may develop faster in the inner parts of the kernel [26]. Moreover, temperature and moisture distribution difference within the kernel occurring during roasting may also enhance localized development of maillard reaction as stated by [27]. This observation coincides with the pattern of internal browning which develops in the inner parts of the cashew kernel while colour of outer parts of the cashew kernel remain similar that of surface of roasted cashew kernel. Therefore, homogenous temperature and moisture distribution during roasting of cashew kernel is important and should be taken into account in the design of cashew kernel roasters. The response of b-value of whole measurement also vertically displaced to significantly lower $b$-value $(p<0.05)$ in cashew paste measurement. The range of b-value was 13.72 to 25.92 in whole kernel measurement, 10.88 to 28.75 in cashew paste measurements over the experimental conditions. The mean b-value of whole kernel measurement $(22.63 \pm 2.79)$ was higher than ground state measurement. The significance of the effect of each variable (temperature and time) on colour attributes of roasted cashew kernel showed that temperature affected L-value, a-value and b-value of whole kernel, moisture content and hardness significantly but did not affect 
significantly browning index and acceptability. Moreover, effect of time was significant for L-value, b-value and moisture content but was insignificant on a-value, browning index and hardness. L-value should be preferred to monitor the colour development during cashew roasting because L-value is analogous to the colour observation made by operator in determining the degree of the roasted product [10]. However, L-value of whole kernel measurement (outside colour) underestimates L-value of cashew paste measurements to due internal browning of cashew kernel during roasting. Therefore, L-value of cashew paste measurements should be preferred during monitoring of roasting process. L-value was also used to monitor non-enzymatic browning in garlic drying [11], peanut roasting [10] and hazelnut roasting [28]. The linear and quadratic terms of the roasting temperature had a significant effect on all colour parameters of the roasted wholekernel and ground state. The interaction terms (roasting temperature and time) for the $\mathrm{L}, \mathrm{b}$-value and $\mathrm{BI}$ of kernel and $\mathrm{L}$ and $\mathrm{b}$-values of the ground-state were found to be significant $(\mathrm{p}<0.05)$. On the overall, except for the a-value of the kernel, and the b-value and BI of the ground-states, all other value studied were significantly $(\mathrm{p}<0.05)$ affected by roasting time. It was observed that roasting temperature is the main factor that influences the L, a, b-values and BI of kernel and L, $a, b$ values of cashew paste but the effect of temperature is more important than time. Similar finding were observed by $[7,22]$ in their studies on hazel nuts. Also, Shakerardekam [29-31] in their studies on pistachio kernels. The plots for colour parameters showed that the shapes of the surface plots for L, b, a-values are similar to each other. All the values showed a decreasing trend at higher temperature and time. The higher roasting temperature and longer exposure time resulted in higher $a-$ and b-values. During thermal processing, temperature is one of the causes of colour degradation in dehydrated products [32]. The colour changes in coffee beans may be due not only to the nonenzymatic browning reaction but also to the destructions of pigment present in coffee beans. Degradation of certain bioactive compounds in the coffee beans might be related to decreasing bioactivity, which was in agreement with the results from [33]. The response surfaces of the $a$-value and $b$ values showed rising ridge behaviour. Sharp increases in these values were observed during roasting. The higher $\mathrm{a}$ - and $\mathrm{b}$-values, which relates to increase in redness and yellowness, respectively are indications of browning. Only the roasting temperature was found to be the main parameters to affect these values. The BI represents purity of brown colour [12]. The shape of the response surface of BI was similar to those of the acceptability. As roasting temperature and time increased, the BI value also increased and this effect was more pronounced at higher temperatures and longer times. The result of the analysis showed that all colour parameter should be considered when monitoring colour changes during roasting of cashew kernel in a hot air oven. Texture is a key component in determining product acceptance. Food texture is a combination of the force required during mastication along with auditory responses perceived during mastication [34]. Texture is the other important control parameter for cashew nut roasting. Hardness is an important parameter that needs to be controlled during roasting of whole-kernel. The changes in textural parameters as a function of the temperature, time and their interactions were almost similar because they show a significant decrease $(\mathrm{p}<0.05$ as roasting temperature and time were increasing indicating a reduction in the strength of the kernel. The decrease in hardness showed the same deformation trend and the force required to break the kernel was smaller as roasting time and temperature were increased. The hardness value of whole-kernel during hot air roasting varies from $19.94 \mathrm{~W}$ for whole-kernel that was roasted at $154^{\circ} \mathrm{C}$ for $40 \mathrm{~min}$ to $32.24 \mathrm{~N}$ for kernel that was roasted at $126^{\circ} \mathrm{C}$ for $40 \mathrm{~min}$. This finding is similar to $[35,36]$ who observed a reverse relationship between roasting temperature and hardness of pistachio nut. The decrease in hardness with the increase in roasting time has also been shown by [37] for sesame seeds and [31] for pistachio nut. Significant linear temperature and time effect were found for hardness model at $5 \%$ level of significance. The significant linear regression equation established in this study could be used for determining hardness of roasted cashew nut. The correlation coefficients of the proposed models that described the textural changes during roasting process were found lower than colour parameters. Model fitting showed no lack of fit, regardless of low correlation-coefficient. Therefore, there models could be used for the prediction of the textural parameters through the experimental design region. Moisture content is a critical factor affecting the flavour; texture and shelf life of most foods, as moisture content generally influences the rate of numerous reactions important to food quality [38]. As cashew kernels are roasted, moisture is released into the atmosphere. The rate at which the moisture is released will depend on both the roast temperature and the amount of time that the samples are roasted. In cashew kernel, moisture content plays an important role in the development of texture. Moisture content decreases during roasting which alters the internal microstructure of the seed [39]. This change in the microstructure helps to create the desired crunchiness of roasted peanuts and may have potential as a marker for textural properties [39] and has been shown to decrease the force required to compress peanuts after roasting [40]. Similar results have been observed in other oilseeds such as almonds, hazelnuts, and cashews, which indicate that long roasting times decreases moisture content and increases crunchiness [41-43]. High roasting temperatures have also been reported to decrease the amount of force needed to compress nuts [40]. This result suggests that moisture content is sensitive to the temperature and time used during roasting. During coffee roasting, there are two major phases: dehydration and pyrolysis. Most of the water is lost during dehydration, at the beginning of the roasting process, reaching very low levels. During pyrolysis, there is still water loss, along with $\mathrm{CO}_{2}$ and $\mathrm{CO}$, however at a very slow rate [44]. The changes in moisture content of whole-kernel during roasting is described by a quadratic model $\left(\mathrm{R}^{2}=0.99\right)$. The results obtained showed that the roasting temperature and time were the main factors affecting the moisture content. Even though the quadratic terms for temperature and time were significant $(\mathrm{p}<0.05)$, the interaction or cross-product was not. The lack of fit test was found to be significant for linear, quadratic and interaction models, hence, the application of RSM for predicting a model to describe the changes. In order to find the optimum point, polynomial regression equation relating the responses to the independent variables were generated to obtain the optimum level of two factors (A and B). Numerical optimization was also carried out to determine the exact optimum level of independent variable leading to desirable roasting conditions. Targets were sets at maximum for sensory properties, minimize fracture force, maximize moisture content, redness (-a) was set at minimum and yellowness (-b) was set in a range and a range for $\mathrm{L}^{*}$ of roasted cashew kernel. Minimization of the fracture force to determine the optimum point was necessary since it showed the brittleness of the cashew kernel, and since there is no standard for colour values of roasted cashew kernel in literature, $\left(\mathrm{L}^{*}\right.$ and $\mathrm{a}^{\star}$ values), they were set in range so that the solution would be in range. The L-value, b-value, BI and hardness of whole kernels and the a-value of ground-state were selected as the control parameters. The optimum quality characteristics of roasted whole-kernel for production of cashew paste are determined by considering the roasting time and temperature only. By using predicted equation determined by RSM, the optimal condition that depended on independent variables was obtained. The region with highest possible desirability was accepted as 
optimum operating conditions for roasting system in this study. The optimum colour and textural parameters of roasted whole-kernel for paste production were as follows: $\mathrm{L}$-value $=32-35$; $\mathrm{b}$-value $=10-16 ; \mathrm{BI}=56$ 67 ; hardness $=57-90 \mathrm{~N}$; and a-value of ground-state $=1-3$. The point with the highest possible desirability functions that could be taken as the optimum conditions for roasting of whole-kernels for the production of cashew paste was found to be $140^{\circ} \mathrm{C}$ and $40 \mathrm{~min}$ (optimal desirability=0.8891). However, for the application of cashew paste in other food products, the recommended range of roasting temperature and time were $140-145^{\circ} \mathrm{C}$ and $30-40 \mathrm{~min}$.

\section{Conclusion}

The results of this study showed that the rate of color changes was significantly affected by temperature and time over the temperature range used in this study. Roasted cashew samples produced significantly lower L-and b-values in ground-state color measurements compared to whole-kernel measurements. The L-value of the whole kernel and of ground-state measurements, representing the lightness of the product, can be used to monitor roasting of cashew nut. The RSM analysis showed that hardness and colour parameters $\left(\mathrm{L}^{*}, \mathrm{a}^{\star}, \mathrm{b}^{\star}\right.$-values, $\left.\mathrm{BI}\right)$ of whole-kernel and $\mathrm{a}^{*}$-values of ground state could be used to monitor the roasting quality of whole-kernel. It also show that roasting temperature is the main factor affecting colour development during roasting of cashew nuts. The results of this study showed Predictive models derived from the second degree polynomials satisfactorily described the L-value, $a$-value and $b$-value of the whole-kernel and ground-state measurement as a function of roasting temperature and time. The effect of roasting temperature and time were found to be more significant than time on the force needed to break cashew kernel. This study showed that the recommended range of roasting temperature and time of whole-kernel for the production of cashew paste was $140-145^{\circ} \mathrm{C}$ and $30-40 \mathrm{~min}$ respectively. The recommended range of roasting temperature and time of whole-kernel for the production of cashew paste was $145^{\circ} \mathrm{C}$ and 40 min with desirability of 0.85 . The study showed that the optimized processing conditions produced acceptable cashew kernel and paste of desirable colour and superior flavour quality with short processing time that will be very useful for direct and commercial consumption It is possible to obtain roasted cashew kernel having similar quality using hot-air oven. The use of hot air drying as a processing for roasting for roasting cashew nut reduces processing time and leads to a cashew nut product with better flavor and uniform colour. Overall, this study suggests there is good potential to optimize cashew nut quality by simply adjusting the time and temperature profiles during roasting.

\section{References}

1. Atul M, Sudhir J, Powar AG (2010) Pollution Sources and Standards of Cashew Nut Processing. American Journal of Environmental Sciences 6: 324-328.

2. TDG (2000) Cashew nut processing technical brief. Journal Chemistry Education 61: 348-358

3. Azam SH, Judge EC (2001) Small Scale Cashew Nut Processing. Intermediate Technology Development Group FAO, Rome.

4. Holland B, Welch AA, Unwin ID (1991) The Composition of Foods. The Royal Society of Chemistry and Ministry of Agriculture, Fisheries and Foods. Xerox Ventura Publishing, Cambridge.

5. Lin JH, Hu BH, Chen WD (1991) Distillation and GC-MS-DS determination of cashew nut shell liquid. Chemistry Industrial Forest Prod 11: 33-39.

6. Francis FJ (1972) Colorimetry of foods. Food Technology 26: 39-48

7. Demir AD, Cronin K (2004) The thermal kinetics of texture change and the analysis of texture variability for raw and roasted hazelnuts. International Journal of Food Science and Technology 39: 371-383.
8. Kosoko SB, Sanni LO, Adebowale AA (2009) Effect of period of steaming and drying temperature on chemical properties of cashew nut. African Journal of Food Science 3: 156-164.

9. Thompson D (1982) Response Surface experimentation. Journal of Food Processing and Preservation 6: 155-188.

10. Moss JR, Otten L (1989) A relationship between color development and moisture during roasting of peanuts. Canadian Institute of Food Science and Technology 1: 34-39.

11. Driscoll RH, Madamba PS (1994) Modeling the browning kinetics of garlic. Food Australia 46: 66-71.

12. Maskan M (2001) Kinetics of colour change of kiwi fruits during hot air and microwave drying. J Food Eng 48: 169-175.

13. Rhim JW, Numes RV, Jones VA (1989) Kinetics of colour changes of grape juices generated using linearly increasing temperature. J Food Sci 54: 776-777.

14. Association of Official Analytical Chemists (2000) Official Methods of Analysis.17 th edn Washington.

15. Bourne MC (1982) Principle of objective texture measurement in Food texture and viscosity: Concept and measurement. Academic Press, New York 45-117.

16. Steel RG, Torie JA (1980) Principle and Practice of statistics. 2nd edn. New York, USA.

17. Saklar S, Katnas S, Ungan S (2001) Determination of optimum hazelnut roasting conditions. International Journal of Food Science and Technology 36: 271-281.

18. Smyth DA, Macku C, Holloway OE (1998) Evaluation of analytical methods for optimizing peanut roasting for snack foods. Peanut Science 25: 70-76.

19. Zaibunnisa AH, Norasikin S, Mamot S (2009) An experimental design approach for the extraction of volatile compounds from turmeric leaves (Curcuma domestica) using Pressurized Liquid Extraction (PLE). Journal of Food Science and Technology 42: 233-238.

20. Ozdemir M (2001) Mathematical analysis of color changes and chemical parameters of roasted hazelnuts.

21. Ozdemir M, Devres O (2000) Kinetics of color changes of hazelnuts during roasting. Journal of Food Engineering 44: 31-38.

22. Ozdemir M, Seyhan FG, Bakan AK (2001) Analysis of internal browning of roasted hazelnuts. Food Chemistry 73: 191-196.

23. Ozdemir M, Ackurt F, Yildiz M (2001) Effect of roasting on some nutrients of hazelnuts (Corylus avellena L). Food Chemistry 73: 185-190.

24. Kahyaoglu T (2008) Optimization of the pistachio nut roasting process using response surface Methodology and gene expression programming. Science Technology 4: 26-33.

25. Elmastry G, Motto E, Blasco J (2006) Effect of hot water treatment on some chemical and mechanical properties of potato. Agriculture Engineering International.

26. Kaya S, Kahyaoglu T (2005) Thermodynamic properties and sorption equilibrium of pestil (grape leather). J Food Eng 71: 200-207.

27. Gogus F, Wedzicha B, Lamb J (1998) Modeling of Maillard reaction during drying of a model matrix. Journal of Food Engineering 35: 445-458.

28. Perren R, Escher F (1996) Rust technology of hazelnuts. Part I. Influence of product temperature and degree of rust on the oxidation stability of roasted nuts. Sugar and Sweets 49: 12-15.

29. Perren R, Escher F (1996) Rust technology of hazelnuts. Sugar and Sweets 49: $142-145$

30. Parren R, Handehin S, Escher F (1996) Optimization of hot air rust of Hazeinussen to improve oxidation stability. Food Technology 29: 1-2.

31. Shakerardekani A, Karim R, Mohd G, Chin NE (2011) Effect of roasting conditions on hardness, moisture content and colour of pistachio kernel. International Food Research Journal 18: 704-710.

32. Makeri MU, Bala S, Kassum AS (2011) The effect of roasting temperatures on the rate of extraction and quality of locally-processed oil from two Nigerian peanut (Arachis hypogeal L) cultivars. African Journal of Food Science 5: 194-199.

33. Vickers ZM (1981) Relationship of chewing sounds to judgment of crispness, crunchiness and hardness. Journal of Food Science 41: 121-124. 
Citation: Olatidoye OP, Awonorin SO, Shittu TA, Ajisegiri ESA, Sobowale SS, et al. (2017) Optimizing the Effect of Temperature-Time Combinations on the Quality Attributes of Roasted Cashew (Anacardium occidentale) Kernel. J Bioprocess Biotech 7: 313. doi:10.4172/2155-9821.1000313

34. Weeren H, Rooij JFM (1998) Flavourings production, composition, applications, regulations. 2nd edn.

35. Wickland SE, Johnoson JJ, Stone MB (2001) Evaluation of roasted and natura hazelnut volatiles by purge-and-trap/gas chromatography/mass spectrometry. Paper presented at the Institute of Food Technologists Annual Meeting and Food Expo, pp: 23-27.

36. Nikzadeh V, Sedaghat N (2008) Physical and sensory changes in pistachio nuts as affected by roasting temperature and storage. American Eurasian Journal of Agricultural and Environmental Sciences 4: 478-483.

37. Man JM, DeMan J (1984) Automated AOM Test for Fat Stability. JAOCS 61: 534-536

38. Kumar S, Debnath S, Hebbar UH (2009) Pulsed Infrared Roasting of Groundnuts and its Quality. International Journal of Food Engineering 5: 1-5.

39. Warner KJH, Dimick PS, Ziegler GR, Mumma RO, Hollender R (1996) Flavor- fade and off flavor in ground roasted peanuts as related to selected pyrazines and aldehydes. J Food Sci 61: 496-472.

40. Saklar S, Ungan S, Katnas S (1999) Instrumental crispness and crunchiness of roasted hazelnuts and correlations with sensory assessment. Journal of Food Science 64: 1015-1019.

41. Wanlapa A, Jindal VK (2006) Instrumental and sensory evaluation of textural changes during roasting of cashew kernels. Journal Texture Studies 37: 263-275.

42. Varela P, Salvador A, Fisman S (2008) On the assessment of fracture in brittle foods: the case of roasted almonds. Food Research International 41: 544-551.

43. Montavon P, Anne FM, Duruz E (2003) Changes in green coffee protein profiles during roasting. Journal of Agricultural and Food Chemistry 51: 2335-2343.

44. Casal S, Amaral J, Oliviera B (2006) Effects of food thermal processing on vitamin E contents. Nova Science Pulishers. pp: 39-67. 